\title{
Pharmacokinetic Aspects of Drugs in the Therapy of Pediatric Obesity
}

Vojinovic Tanja*, Lalatovic Ninoslava and Joksovic Marko

University of Montenegro Faculty of Medicine, Montenegro

\section{Introduction}

Childhood obesity represents a global public health crisis. It is caused by an imbalance

ISSN: 2640-9208

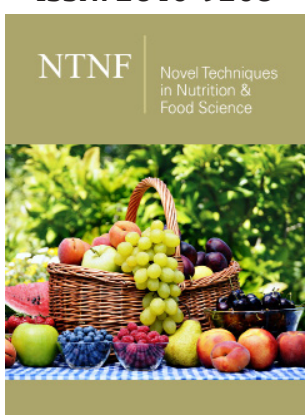

*Corresponding author: Vojinovic Tanja, University of Montenegro Faculty of Medicine, Montenegro

Submission: :-1-n November 05, 2020

Published: 監January 8, 2021

Volume 5 - Issue 3

How to cite this article: Vojinovic Tanja, Lalatovic Ninoslava, Joksovic Marko. Pharmacokinetic Aspects of Drugs in the Therapy of Pediatric Obesity. Nov Tech Nutri Food Sci. 5(3). NTNF. 000615. 2021. DOI: $10.31031 /$ NTNF.2021.05.000615

Copyright@ Vojinovic Tanja. This article is distributed under the terms of the Creative Commons Attribution 4.0 International License, which permits unrestricted use and redistribution provided that the original author and source are credited. between calories consumed and consumed [1]. The trend of increasing prevalence of obesity leads to an increased risk of endocrine, metabolic, cardiovascular, respiratory, gastrointestinal, orthopedic, skin, neurological health disorders [2]. Children who are obese are likely to develop diseases such as type 2 diabetes mellitus and cardiovascular disease at a young age [3]. Disorders that occur as a result of obesity are numerous and severe [4]. The table shows the complications that occur as a result of obesity (Table 1); [4].

Table 1: Obesity complications of children and adolescents [4].

\begin{tabular}{|c|c|}
\hline Physiological/Organic system & Complication/Disorders \\
\hline \multirow{4}{*}{ Metabolic } & Insulin resistance \\
\hline & Type 2 diabetes \\
\hline & Dyslipidemia \\
\hline & Metabolic syndrome \\
\hline \multirow{4}{*}{ Cardiovascular } & Hypertension \\
\hline & Left ventricular hypertrophy \\
\hline & Atherosclerosis \\
\hline & Asthma \\
\hline Pulmonary & Obstructive sleep apnea \\
\hline \multirow{2}{*}{ Gastrointestinal } & Nonalcoholic fatty liver disease \\
\hline & Gastroesophageal reflux \\
\hline \multirow{2}{*}{ Skeletal } & Tibia vara (Blount disease) \\
\hline & Slipped capital-femoral epiphysis \\
\hline \multirow{2}{*}{ Other } & Polycystic ovary syndrome \\
\hline & Pseudotumor cerebri \\
\hline
\end{tabular}

Treating obesity in the pediatric population is one of the most important health priorities. The therapeutic approach to obesity should be comprehensive, first of all it is necessary to change the diet and increased physical activity and thus weight reduction, pharmacological approach, but it is limited due to the efficacy and safety of drugs for weight loss in children and bariatric surgery [5].

\section{Pharmacotherapy of Pediatric Obesity}

Obesity therapy drugs have the potential to reduce body weight and reduce weight-related comorbidities. However, these drugs can have serious adverse effects, and most have not been adequately tested for efficacy and safety in the pediatric population. Data on long-term experience with weight loss drugs in this population are still lacking. Potential side effects and risks, the patient's current body weight, previous weight, therapeutic options for trying to lose weight, age, puberty, and comorbidities must be considered when prescribing these drugs [6]. Metformin is an oral antihyperglycaemic drug approved by the Food Drug Administration and the European Medicines Agency in children older than 10 years for use in type 2 diabetes 
mellitus. However, metformin has been shown to lead to weight loss [7]. The only drug currently approved by the U.S. Food and Drug Administration (FDA) to treat obesity in the younger population, ages 12 and older, is orlistat [8]. Orlistat is also approved by the EMA but only for patients 18 years of age and older. In addition to orlistat, the FDA has approved four drugs in the treatment of adult obesity-liraglutide, lorcaserin, naltrexone-buproprion and phentermine-topiramate, and the EMA has approved liraglutide and naltrexone-bupropion. These drugs are possible potential candidates for the treatment of pediatric obesity [9].

\section{Influence of obesity on drug pharmacokinetic parameters in the pediatric population}

Pharmacokinetic processes of absorption, distribution, metabolism and excretion depend on the size of the body, the process $[10,11]$.

\section{Absorption}

In adult obese patients, small changes in absorption were observed with oral, subcutaneous and intramuscular administration of drugs, which had no clinical significance. No information is currently available to compare absorption in obese and normal weight children [12].

\section{Distribution}

The volume of distribution is a key factor in calculating the initial dose of the drug. It primarily depends on the solubility of the drug. Obese people have a higher percentage of body fat and generally a higher volume of distribution of lipophilic drugs, due to the distribution of these drugs in adipose tissue. The volume of distribution of hydrophilic drugs is variable and depends on the total percentage of water in the body. Dosage recommendations for most pediatric medications are weight-based. In pediatric obesity, the dosage depends on the solubility of the drug. Ideal body weight should be used to determine the dose of hydrophilic drugs, dose calculation should be based on current total body weight for lipophilic drugs, and adjusted body weight should be used for partially lipophilic drugs [13].

\section{Metabolism}

Drugs that are primarily metabolized in the liver should be used with caution until the age of twelve. Variations in the metabolism of some drugs have been observed in obese individuals through changes in the activities of enzymes involved in phase I and/or II metabolism [14].

\section{Excretion}

Drug clearance is the primary determinant to consider when designing a maintenance dose regimen, largely controlled by hepatic and renal physiology. The effects of obesity on renal tubular secretion, tubular reabsorption, and glomerular filtration have not been fully elucidated. For drugs that are eliminated by the renal, the effect of obesity on glomerular filtration, tubular secretion and tubular reabsorption are of great importance. Significantly higher mean serum creatinine concentrations were observed in obese children and adolescents compared to normal weight subjects. The variability in clearance in the obese pediatric population can be explained by the principles of allometry and the maturation process of this population [15]. The elimination half-life of a drug depends on the volume of distribution and clearance. As these are two biologically independent entities, changes in drug elimination half-life in obese individuals may reflect changes in distribution volume and clearance, or both [16]. Current research results indicate that pediatric obesity may alter the volume of distribution and clearance and elimination half-lives of a large number of drugs, requiring dosage adjustment, especially for drugs with a low therapeutic index.

\section{Conclusion}

Obesity is one of the leading diseases of modern times. Obesity leads to a significant increase in morbidity and mortality, various health complications and diseases, with a significant reduction in quality of life. Pediatric obesity therapy is an imperative in health care and crucial for improving the health of children and adolescents. There are different approaches in the treatment of obesity, and they are: non-pharmacological, pharmacological measures and surgical approach. The use of drugs in the treatment of obesity in pediatric obesity is limited due to the manifestation of side effects. The side effects that may occur are correlated with the effect of the drug and/or its pharmacokinetic profile. As the pharmacokinetics are altered in some parts in the obese population, the risk for use in adolescents and children increases. Pharmacokinetic changes in obese pediatric patients have clinical significance affecting the efficacy and safety of therapy. Pharmacokinetic processes depend on body size, maturation process, and organ function in pediatric patients. It is difficult to make a generalization about pharmacokinetic differences between obese children and children of normal weight, due to the lack of studies involving obese children. In the absence of clinical trials in the pediatric population, for ethical reasons, available study data in adult patients can be extrapolated, including the effects of growth and development on pharmacokinetics relevant to the age of the child.

\section{References}

1. Karnik S, Kanekar A (2012) Childhood obesity: A global public health crisis. Int J Prev Med 3(1): 1-7.

2. Sahoo K, Sahoo B, Choudhury AK, Sofi NY, Kumar R, et al. (2015) Childhood obesity: causes and consequences. J Family Med Prim Care 4(2): 187-192.

3. Engin A (2017) The definition and prevalence of obesity and metabolic syndrome. Adv Exp Med Biol 960: 1-17.

4. Daniels SR (2009) Complications of obesity in children and adolescents. Int J Obes (Lond) 1: S60-S65.

5. Kumar S, Kelly AS (2017) Review of childhood obesity: from epidemiology, etiology, and comorbidities to clinical assessment and treatment. Mayo Clin Proc 92(2): 251-265. 
6. Kelly AS, Fox CK, Rudser KD, Gross AC, Ryder JR (2016) Pediatric obesity pharmacotherapy: current state of the field, review of the literature, and clinical trial considerations. Int J Obes (Lond) 40(7): 1043-1050.

7. Villaescusa BP, Cañete MD, Villarraso JC, Hoyos R, Latorre M, et al (2017) Metformin for obesity in prepubertal and pubertal children: a randomized controlled Trial. Pediatrics 140(1): e20164285.

8. Duffie JR, Calis KA, Uwaifo GI, Sebring NG, Fallon EM, et al. (2004) Efficacy of orlistat as an adjunct to behavioral treatment in overweight African American and Caucasian adolescents with obesity-related comorbid conditions. J Pediatr Endocrinol Metab 17(3): 307-319.

9. Bray GA, Frühbeck G, Ryan DH, Wilding JPH (2016) Management of obesity. Lancet 387(10031): 1947-1956.

10. Vucicevic K, Miljkovic B (2012) Pharmacokinetic aspects in dosing regimen in paediatrics. Arh Farm 62(4): 306-321.
11. Anderson BJ, Holford NH (2011) Tips and traps analyzing pediatric PK data. Paediatr Anaesth 21(3): 222-237.

12. Lee JB, Winstead PS, Cook AM (2006) Pharmacokinetic alterations in obesity. Orthopedics 29(11): 984-988.

13. Kendrick JG, Carr RR, Ensom MH (2010) Pharmacokinetics and drug dosing in obese children. J Pediatr Pharmacol Ther 15(2): 94-109.

14. Rusic B, Denić K, Djordjevic S (2014) The importance of enzyme cytochrome P450 in drug metabolism. MD-Medical Data 6(1): 95-98.

15. Cornelis S, Hoogd SD, Roger JM, Knibbe BC, Knibbe AJ (2018) Obesity and drug pharmacology: a review of the influence of obesity on pharmacokinetic and pharmacodynamic parameters. Expert Opinion on Drug Metabolism \& Toxicology 14(3): 275-258.

16. Hanley MJ, Abernethy DR, Greenblatt DJ (2010) Effect of obesity on the pharmacokinetics of drugs in humans. Clin Pharmacokinet 49(2): 71-87.

For possible submissions Click below: 